\title{
Rehabilitation Intervention in Animal Model Can Improve Neuromotor and Cognitive Functions After Traumatic Brain Injury: Pilot Study
}

\author{
M. LIPPERT-GRÜNER ${ }^{1,3}$, M. MÄGELE ${ }^{2}$, O. ŠVESTKOVÁ ${ }^{3}$, Y. ANGEROVÁ \\ T. ESTER-BODE ${ }^{4}$, D. N. ANGELOV ${ }^{5}$
}

${ }^{1}$ Department of Neurosurgery, Faculty of Medicine, University of Cologne, Germany, ${ }^{2}$ Department of Surgery, Merheim Medical Center, University of Witten-Herdecke, Cologne, Germany, ${ }^{3}$ Department of Rehabilitation Medicine, First Faculty of Medicine, Charles University Prague and General Teaching Hospital in Prague, Czech Republic, ${ }^{4}$ Department of Neurology, Merheim Medical Center, University of Witten-Herdecke, Cologne, Germany, ${ }^{5}$ Department of Anatomy I, University of Cologne, Cologne, Germany

Received May 6, 2009

Accepted August 16, 2010

On-line November 29, 2010

\section{Summary}

The aim of the present study was to quantify the effect of multisensory rehabilitation on rats' cognition after an experimental brain trauma and to assess its possible clinical implications. The complex intermittent multisensory rehabilitation consisted of currently used major therapeutic procedures targeted at the improvement of cognitive functions; including multisensory and motor stimulation and enriched environment. We have confirmed this positive effect of early multisensory rehabilitation on the recovery of motor functions after traumatic brain injury. However, we have been able to prove a positive effect on the recovery of cognitive functions only with respect to the frequency of efficient search strategies in a Barnes maze test, while results for search time and travelled distance were not significantly different between study groups. We have concluded that the positive effects of an early treatment of functional deficits are comparable with the clinical results in early neurorehabilitation in human patients after brain trauma. It might therefore be reasonable to apply these experimental results to human medical neurorehabilitation care.

\section{Key words}

Brain trauma recovery - Multisensory rehabilitation model • Enriched environment

\section{Corresponding author}

O. Švestková, Charles University and General Teaching Hospital in Prague, Department of Rehabilitation Medicine, Albertov 7, 12800 Prague, Czech Republic. Fax: 0042224917 898. E-mail: olga.svestkova@lf1.cuni.cz

\section{Introduction}

The rehabilitation procedures commonly used after a heavy brain trauma take the advantage of the optimal utilization of neural plasticity mechanisms (Saatman et al. 2001, Stein et al. 2002). Current research in the literature indicates that the intermittent multimodal sensory stimulation influences the regeneration of the damaged central nervous system and advances its reorganization and functional recovery (Maegele et al. 2002). This knowledge is mainly empirical because the underlying mechanisms are far from being thoroughly understood. At present the effects of multisensory stimulation on brain plasticity have been studied mainly in an enriched environment model (Hamm et al. 1996, Czeh et al. 1998, Passineau et al. 2001) with its continuous availability of stimulating activity and within spacious housing equipped with plenty of toys to play with. However, the enriched environment model is not 
suitable for an assessment of the effect of multisensory stimulation therapy, as all the sensory stimuli are present continuously. In clinical neurorehabilitation, the sensory stimulation is administered intermittently, the length of the treatment units being clearly separated in time and their length adjusted to the patient's current performance level (Lippert-Grüner and Terhaag 2000, Lippert-Grüner et al. 2002a,b, 2007).

The aim of the present study was to quantify the effect of multisensory rehabilitation on rats' cognition after an experimental brain trauma and to assess its possible clinical implications within comparable conditions.

\section{Methods}

We did our research in 12 adult male SpragueDawley rats, each weighing 350-450 g, using conventional breeding. We divided them into two groups, six animals each. We used this species and strain of experimental animal because a fluid percussion brain trauma model has been successfully established in them previously and valid experimental results are already available for discussion. The animals were taken to the experimental environment and kept in standard conditions one week prior to the experiment. Before and during the whole experiment, water and food were freely available to the animals. In line with official guidelines, the animals were kept at $20-23{ }^{\circ} \mathrm{C}$ room temperature, $50-60 \%$ relative air humidity and $12 \mathrm{~h}$ light/dark cycle. The ambient illumination level during the light period was 50-100 lux with lights turned on at 7 a.m. All the procedures and testing were performed during the light period.

All experimental procedures conformed with the guidelines of the Cologne University and the state's animal protection and ethics committee. All efforts were undertaken to minimize animal discomfort and to reduce the total number of animals used.

\section{Brain trauma model}

The lateral fluid-percussion (LFP) brain injury model is one of the most widely used and well characterized models of experimental traumatic brain injury. It has a good reproducibility and can cope a lot of important aspects of human traumatic brain injury (McIntosh et al. 1989). The trauma was induced by the fall of a metal pendulum against a piston inducing a pulse of increased intracranial pressure of 21-23 ms duration through rapid injection of saline into the closed cranial cavity thus resulting in a brief displacement and deformation of neural tissue. The pressure pulse was measured extracranially by a transducer (Gould) housed in the injury device and recorded by a computer oscilloscope emulation program (RC Electronics). FluidPercussion-Model produced by the lateral shift of brain tissue causes a diffuse trauma of the white matter near to cortex and the basal ganglia, as well as intraparenchymal petechial bleedings in cortex, white matter, hippocampus and basal ganglia and brainstem. A subarachnoid bleeding can also be seen. Cellular death, necrosis and impairment of long axonal pathways can be found in the cortex. These lesions are irreversible. The axonal trauma is a most important characteristic of Fluid-PercussionModel compared to other experimental brain trauma models (McIntosh et al. 1989, Hicks et al. 1996).

This traumatic injury is biomechanically, physiologically, neurologically and morphopathologically comparable with a corresponding brain trauma in humans (Sullivan et al. 1976). In brief, animals were anesthetized with sodium pentobarbital $(60 \mathrm{mg} / \mathrm{kg}$, i.p.), placed in a stereotaxic frame, and the scalp and temporal muscle were uncovered. A hollow female Luer-Lock fitting was rigidly fixed with dental cement to a $4.8-\mathrm{mm}$ craniotomy centered between bregma and lambda and $2.5 \mathrm{~mm}$ lateral to the sagittal sinus, keeping the dura mater intact. The fluid-percussion device (Fig. 1) consists of a plexiglas cylinder filled with isotonic saline. One end of the cylinder is connected to a metal housing terminated with a male Luer-Lock fitting. Prior to the induction of trauma the male Luer-Lock was connected to the female LuerLock anchored in the rat skull, creating a closed system filled with isotonic saline in connection with the dura. The trauma was induced by the fall of a metal pendulum against a piston inducing a pulse of increased intracranial pressure of 21-23 ms duration through rapid injection of saline into the closed cranial cavity thus resulting in a brief displacement and deformation of neural tissue. The pressure pulse was measured extracranially by a transducer (Gould) housed in the injury device and recorded by a computer oscilloscope emulation program (RC Electronics). Following injury at a moderate level (2.1 $\mathrm{atm})$, the incision was closed with interrupted 4.0 silk sutures, and the animals were placed onto a heated pad to maintain body temperature for $1 \mathrm{~h}$ following surgery. The trauma was induced in all animals on experimental day 0 . All animals were monitored for at least $6 \mathrm{~h}$ postsurgery, then daily. 


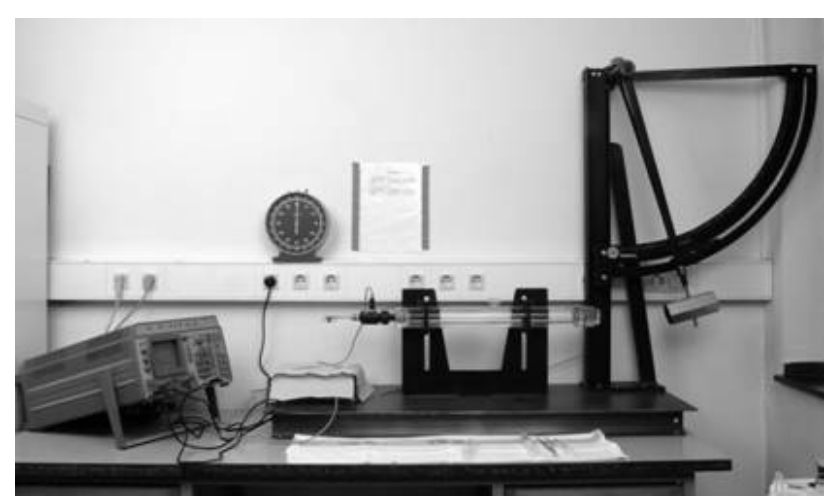

Fig. 1. The fluid percussion model.

\section{Experimental groups}

Twenty-four hours after trauma, on experimental day 1 , the animals were randomly divided into two experimental groups:

Group 1: Standard housing. Animals were single housed in conventional cages without any special procedures given to them.

Group 2: Early multisensory rehabilitation model (EMR). Animals were housed in a spacious enriched environment and early intermittent multisensory rehabilitation and motor stimulation were administered to them, as described below.

The experiment lasted 15 days after the trauma.

\section{Early multisensory rehabilitation}

The early rehabilitation based on the repeated multisensory and motor stimulation complemented by an enriched environment changing over time started $24 \mathrm{~h}$ after trauma in the EMR group, just after the animals had been randomly divided into both experimental groups. We have previously described our early multisensory rehabilitation (EMR) model (Fig. 2) in detail (LippertGrüner and Terhaag 2000, Lippert-Grüner et al. 2007). The EMR animals were kept together thus allowing them to freely interact within a spacious housing with plenty of toys to play with and a dark quiet room to rest in. Multimodal stimulation presented to the animals three times daily consisted of acoustic stimulation (intermittent buzzer sound $80 \mathrm{~dB}$ loud $30 \mathrm{~s}$ on, $30 \mathrm{~s}$ off, followed by a 20 -min pause), visual stimulation ( $60 \mathrm{~W}$ bulb blinking at a frequency of $1 \mathrm{~Hz}$ followed by a 20-min pause) and olfactory stimulation (mint essence). To stimulate motor and executive functions, five days of motor training on a rotating rod was administered on experiment days 5 through 9 (post-trauma).

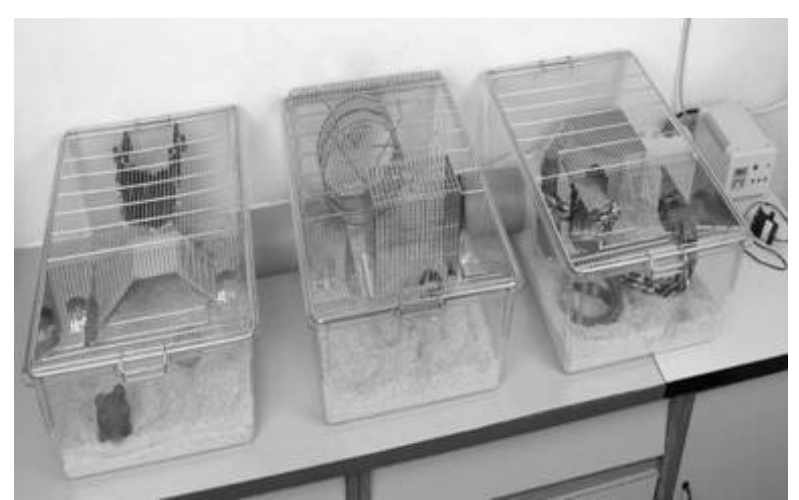

Fig. 2. Early multisensory rehabilitation model (EMR).

\section{Examination of neuromotor functions}

Neuromotor abilities were evaluated in all animals using a well-established neuroscore battery of tests (Okiyama et al. 1992, Simson et al. 1995). Briefly, this test battery includes individual tests targeted at forelimb function, each side at a time, hindlimb function, resistance to lateral pulsion and ability to stand on an inclined plane (Okiyama et al. 1992, Simson et al. 1995). Scoring for each individual animal ranged from 4 points (normal performance) to 0 points (severely impaired performance) for each of the tested modalities. It has been previously suggested that the composite neurological motor score (ranging from 0 to 28 points) obtained as a sum of all the test scores is a good cumulative indicator of neuromotor status and correlates well with the severity of the trauma (Sullivan et al. 1976, McIntosh et al. 1989). The investigator did not know which group a tested animal belonged to. Neuromotor functions were assessed in both standard housing and early multisensory rehabilitation animals $24 \mathrm{~h}$ prior to trauma and $24 \mathrm{~h}, 7$ and 15 days after trauma.

\section{Examination of cognitive functions}

We have examined cognitive deficits with a special focus on spatial memory and learning with a Barnes circular maze test. The circular maze (Barnes 1979) has been adapted to assess spatial reference memory following traumatic brain injury (Fig. 3). The maze represents an efficient and approved alternative to the common used water maze test with less stress to the animal, less physical demand and less trials over days for satisfactory training (Fox et al. 1998). In brief, animals were trained to locate a dark escape chamber, hidden underneath a hole positioned around the perimeter of a disk, brightly illuminated by four overhead halogen lamps to provide a low-level aversive stimulus. Our maze was manufactured 
from white acrylic plastic to form a disk $1.5 \mathrm{~cm}$ thick and $115 \mathrm{~cm}$ in diameter with 18 evenly spaced $7 \mathrm{~cm}$ holes at its edges. The latencies to enter the escape box were recorded by the investigator blinded to treatment. Additionally, all trials were recorded simultaneously by a video camera installed directly overhead the center of the maze. Two daily training trials of the Barnes circular maze test were performed in two five-day series, on consecutive experiment days -1 through -5 (pre-trauma) and 11 through 15 (post-trauma). A trial was started by placing the animal in the center of the maze covered under a cylindrical start chamber; after a $10 \mathrm{~s}$ delay, the start chamber was raised remotely using a pulley system. A training session ended after the animal had entered the escape chamber or when a predetermined (300 s) time had elapsed, whichever came first. There was a 4-min intertrial interval for each animal. All surfaces were routinely cleaned with distilled water before and after each trial to eliminate possible olfactory cues from preceding animals.

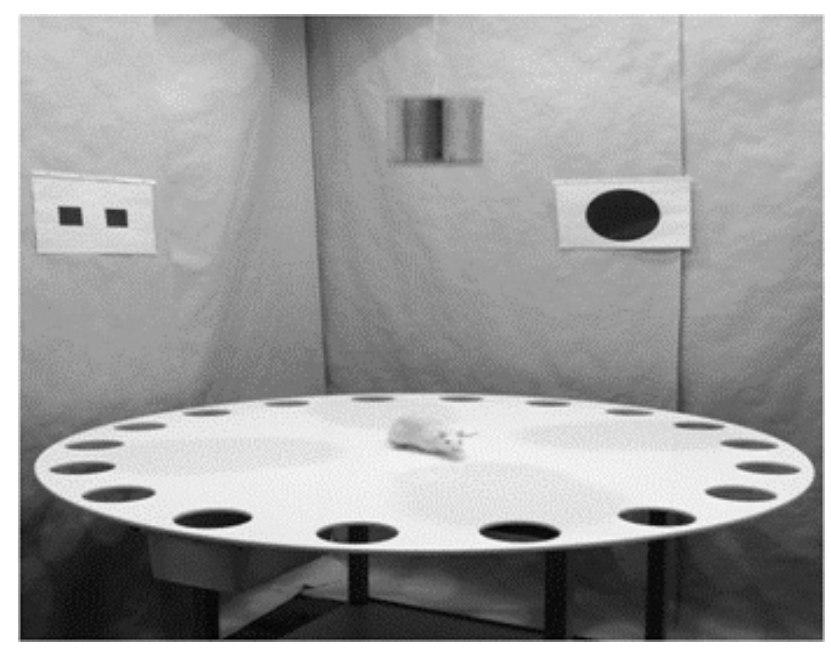

Fig. 3. Start position of Barnes circular maze test.

The latencies to enter the escape box, the path length and the trajectory were recorded. A trial was started by placing the animal in the centre of the maze covered under a cylindrical start chamber. After a 10-s delay, the start chamber was raised remotely. A training session ended after the animal had either entered the escape chamber or when a predetermined (300 s) time had elapsed, whichever came first. There was a 4-min intertrial interval for each animal.

\section{Statistical analysis}

Data obtained from standard housing ( $\mathrm{SH})$, and early multisensory rehabilitation (EMR) animals were tested for differences using one-way descriptive statistics and one-way ANOVA. A level of significance of $\mathrm{p}<0.05$ was used for all analyses. All computations were performed using 11.0 SPSS $^{\circledR}$-software.

\section{Results}

\section{Neuromotor functions}

Examination results of neuromotor functions (neuroscores) are shown in Table 1. As expected, one day before the trauma, all animals scored a neuroscore with the full number of points ( 28 points). The first day after trauma, the sensorimotor deficit in both groups was of a well comparable magnitude, as expressed by the mean neuroscore of 14.31 (in standard housing animals) and 14.85 (in rehabilitation animals), which indicates a moderate sensorimotor posttraumatic deficit.

Table 1. Mean scores of neuromotor functions (Neuroscore) in standard housing and early multisensory rehabilitation groups.

\begin{tabular}{cll}
\hline $\begin{array}{l}\text { Experimental } \\
\text { day }\end{array}$ & $\begin{array}{l}\text { Standard } \\
\text { housing }\end{array}$ & $\begin{array}{l}\text { Early } \\
\text { multisensory } \\
\text { rehabilitation }\end{array}$ \\
\hline-1 & $28.00 \pm 0.00$ & $28.00 \pm 0.00$ \\
1 & $14.31 \pm 2.88$ & $14.85 \pm 2.92$ \\
7 & $12.92 \pm 3.03$ & $16.71 \pm 2.31$ \\
15 & $14.25 \pm 2.01$ & $18.56 \pm 1.80$ \\
\hline
\end{tabular}

Data are means \pm S.D.

To assess the differences in posttraumatic neuromotor deficit, we performed a one-way analysis of variance. We found no statistical difference in posttraumatic neuromotor deficit $24 \mathrm{~h}$ after brain injury). The overall difference in the time courses of motor function deficit between both groups was significantly different $(p<0.05)$. Fifteen days after injury the mean neuromotor score for the standard housing group was 14.25 points compared with the significantly higher score of 18.56 points in the early multisensory rehabilitation group $(\mathrm{p}<0.05)$.

\section{Cognitive functions}

The Barnes circular maze has been adapted to assess spatial reference memory following traumatic brain injury. The impairment of the spatial memory can 
Table 2. Results of Barnes circular maze test in standard housing $(\mathrm{SH}, \mathrm{n}=6)$ and early multisensory rehabilitation (EMR, $n=6)$ groups.

\begin{tabular}{|c|c|c|c|c|c|c|}
\hline \multirow[t]{2}{*}{ Experimental day } & \multicolumn{2}{|c|}{$\begin{array}{l}\text { Latency } \\
\text { (seconds) }\end{array}$} & \multicolumn{2}{|c|}{$\begin{array}{l}\text { Distance } \\
\text { (meters) }\end{array}$} & \multicolumn{2}{|c|}{$\begin{array}{c}\text { Number of } \\
\text { mistakes }\end{array}$} \\
\hline & SH & EMR & SH & EMR & SH & EMR \\
\hline \multirow[t]{2}{*}{-5} & 32.92 & 31.75 & 3.43 & 2.50 & 4.92 & 4.50 \\
\hline & \pm 15.00 & \pm 21.35 & \pm 2.01 & \pm 0.90 & \pm 2.33 & \pm 1.18 \\
\hline \multirow[t]{2}{*}{-4} & 21.50 & 22.25 & 2.48 & 2.86 & 4.17 & 5.00 \\
\hline & \pm 12.24 & \pm 9.73 & \pm 0.88 & \pm 1.30 & \pm 2.25 & \pm 2.64 \\
\hline \multirow[t]{2}{*}{-3} & 15.50 & 13.33 & 2.47 & 1.91 & 3.83 & 3.75 \\
\hline & \pm 8.76 & \pm 5.63 & \pm 1.54 & \pm 0.86 & \pm 2.62 & \pm 2.66 \\
\hline \multirow[t]{2}{*}{-2} & 12.83 & 19.50 & 1.98 & 2.72 & 4.58 & 4.33 \\
\hline & \pm 3.88 & \pm 6.58 & \pm 0.53 & \pm 0.91 & \pm 2.26 & \pm 3.12 \\
\hline \multirow[t]{2}{*}{-1} & 15.33 & 19.75 & 2.36 & 2.80 & 4.5 & 4.58 \\
\hline & \pm 3.57 & \pm 5.44 & \pm 0.60 & \pm 0.36 & \pm 1.73 & \pm 2.90 \\
\hline \multirow[t]{2}{*}{11} & 24.67 & 23.00 & 3.22 & 2.87 & 5.92 & 6.00 \\
\hline & \pm 9.36 & \pm 12.21 & \pm 1.42 & \pm 1.30 & \pm 3.10 & \pm 2.58 \\
\hline \multirow[t]{2}{*}{12} & 22.58 & 21.33 & 3.24 & 3.09 & 4.75 & 5.25 \\
\hline & \pm 11.08 & \pm 9.65 & \pm 2.10 & \pm 1.19 & \pm 2.54 & \pm 4.22 \\
\hline \multirow[t]{2}{*}{13} & 15.33 & 15.83 & 2.26 & 1.94 & 3.00 & 2.75 \\
\hline & \pm 7.02 & \pm 9.486 & \pm 1.26 & \pm 1.21 & \pm 1.18 & \pm 1.66 \\
\hline \multirow[t]{2}{*}{14} & 15.17 & 13.67 & 2.33 & 1.86 & 3.25 & 3.33 \\
\hline & \pm 4.65 & \pm 7.95 & \pm 1.01 & \pm 0.59 & \pm 1.33 & \pm 2.82 \\
\hline \multirow[t]{2}{*}{15} & 15.5 & 13.50 & 2.60 & 2.45 & 3.75 & 3.25 \\
\hline & \pm 4.93 & \pm 2.77 & \pm 1.06 & \pm 0.77 & \pm 1.83 & \pm 1.29 \\
\hline
\end{tabular}

Data are means \pm S.D.

be probably related to the intraparenchymal petechial bleedings and the cellular loss in the hippocampus. The search strategy represents the function of spatial memory in addition to the ability of planning.

Spatial cognition examined in the Barnes circular maze test was primarily assessed by the search time (in seconds) needed by the animal to find the protective box. Furthermore, the distance (in meters) travelled by the animal and number of erroneously chosen places was recorded and analyzed and the search strategy chosen by the animal was classified as either random (a), serial (b), or spatial (c) according to predefined criteria (see Fig. 5 caption for details). Two successive training sessions were carried out each day. The mean of the two daily values was entered into the following statistical analysis. The results are summarized in Table 2 and Figure 4.

The first series of the Barnes circular maze test were carried out during the five consecutive days just preceding the induction of the experimental brain trauma (on experiment days -5 through -1 ). In this pretraumatic cognitive function test series, the standard housing group achieved a decrease in latency of $17.59 \mathrm{~s}$ and the early multimodal rehabilitation group of $12.00 \mathrm{~s}$. The path length shortening was $1.07 \mathrm{~m}$ in the standard housing group, whereas no path length shortening was recorded in the early multisensory rehabilitation group. The decrease in the number of errors per trial was 0.42 in the SH group compared with no change in the EMR group. Although the EMR group performed slightly worse before the trauma, the results between groups in latency decrease, path length shortening and number of errors per trial were not statistically significant. The percentages of employed search strategies (Fig. 5) were fully comparable in both groups. Thus the cognitive capacity examined in all four parameters of the Barnes circular maze test was comparable in both groups before the trauma.

The next series of the Barnes circular maze test was carried out on days 11 through 15 after the trauma. Again, we compared the level of improvement in all three recorded parameters (Table 2). Initial values for both groups were the same, mean latency for the standard 

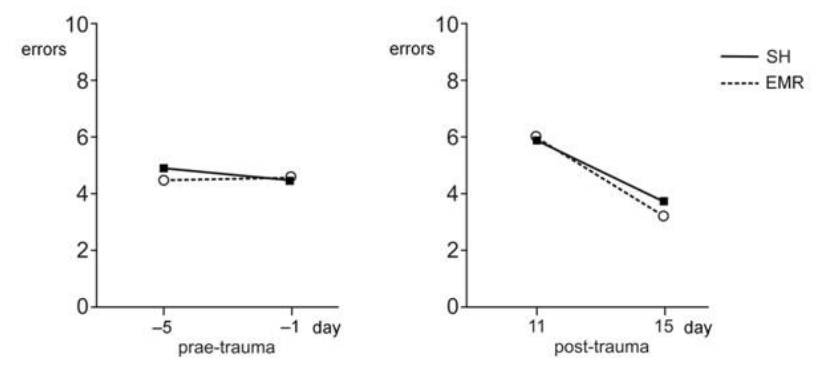

Fig. 4. Mean number of errors in Barnes circular maze test in both standard housing $(\mathrm{SH})$ and early multisensory rehabilitation (EMR) groups.

housing group being $24.67 \mathrm{~s}$ and $23.00 \mathrm{~s}$ for the early multisensory rehabilitation group. During the five consecutive testing days, the standard housing group improvement in latency was $9.17 \mathrm{~s}$ as in multisensory rehabilitation group $(9.5 \mathrm{~s})$. The path length improvement ( 0.62 vs. $0.42 \mathrm{~m}$ ) was comparable in both groups as well. In the number of errors, the EMR group performed slightly, but statistically not significantly better, by achieving a mean 2.75-point improvement compared to the $\mathrm{SH}$ group with its improvement of 2.17 points (Fig. 4).

The percentages of the chosen search strategies were markedly different among the groups. We have evaluated the cumulative percentages of search strategies summed up for pre-trauma and post-trauma trials. The statistical analysis employed here was the non-parametric $\chi^{2}$-test and revealed a highly significant difference between both groups $(\mathrm{p}<0.02)$. The difference was especially apparent in the decrease of random search usage. Random search was employed in $11.7 \%$ of the standard housing and in $13.3 \%$ of the early multimodal rehabilitation group before trauma (Fig. 5). After trauma, random search usage in standard housing animals increased to $16.7 \%$, while its percentage in the early multimodal rehabilitation declined to only $3.3 \%$ (Fig. 5). Thus the very inefficient random search was virtually abandoned after early multisensory rehabilitation.

\section{Discussion}

The aim of the present study was to evaluate the effect of an experimental early multisensory rehabilitation after brain trauma. The rehabilitation model consisted of currently used major therapeutic procedures targeted at the improvement of cognitive functions. Previously published studies examining the effect of enriched environment on animal behavior outnumber by far those that take the advantage of complex intermittent

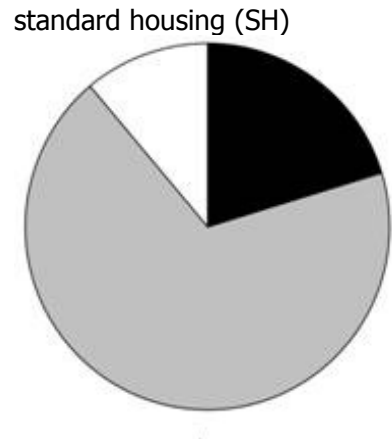

prae-trauma

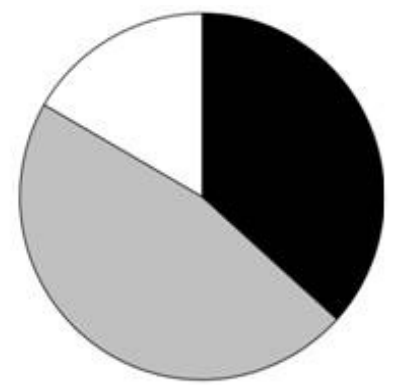

post-trauma early multisensory rehabilitation (EMR)

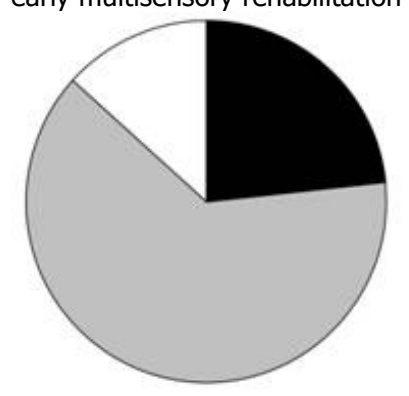

prae-trauma

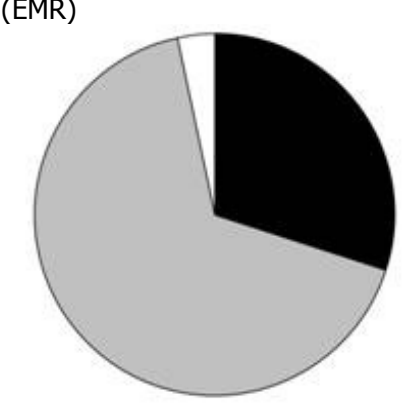

post-trauma
Fig. 5. Percentage of chosen search strategies in standard housing (SH) and early multisensory rehabilitation (EMR) shown cumulatively pre-trauma and post-trauma. 1) random search = white (non-targeted search, multiple changes of search direction, crossings of the centre of the disk, perseveration); 2) serial search = grey (targeted search, the subject examines each or each other hole sequentially in one direction, one change of search direction is acceptable provided the following search is serial or spatial); 3) spatial search = black (targeted search starting not further than two holes from the target box, it is not necessary for the subject to start search in the target sector, however, once there, it must not leave it again).

multisensory rehabilitation and motor stimulation. The positive effect of enriched environment on cerebral regeneration has been repeatedly demonstrated both at the functional, motor and cognitive levels (Gentile et al. 1987, Grabowski et al. 1995, Ohlsson and Johansson 1995, Johansson and Ohlsson 1996) and at the levels of neuroanatomy, neurophysiology and neuropharmacology (Bennett et al. 1964, Greenough and Volkmar 1973, Kolb 1995, Young et al. 1999, Zeng et al. 2000, Zhao et al. 2001, Johansson and Belichenko 2002). However, some studies found a negative effect of enriched environment on functional recovery. When we looked more carefully at those studies in order to resolve this apparent discrepancy, we found that they possibly used very simple and uniform stimuli only (Denenberg and Zarrow 1971, Daly 1973), thus a rapid habituation in the absence of complex stimuli effectively prevented the sensomotor and cognitive recovery. This is why enriched environment itself, in our opinion, is not a sufficient 
model for early multisensory neurorehabilitation, as we will discuss in more detail later.

In the present study we have used an experimental model of early multisensory rehabilitation aimed at the assessment of its effect on cognitive and sensomotor abilities in the early phases after a traumatic brain injury. Standardization of the magnitude of brain trauma was achieved by the use of a fluid percussion model and its leveling is seen in the uniform scores of neuromotor functions one day after trauma. There was not only a consistency within groups, but the interindividual variability was remarkable small (Table 1). In accordance with our previous studies (Lippert-Grüner and Terhaag 2000, Lippert-Grüner et al. 2007), we have observed continuous improvement of functional deficits in neuromotor functions in both groups (Table 2) during 15 days after the trauma. However, the animals living in an early multisensory rehabilitation model demonstrated significantly better results. The continuously improving sensomotor functions are comparable with the results of Biernaskie et al. (2004). Their model, although different in many details, is in principle comparable with the rehabilitation model used in our study. However, their work cannot be used as a reference to our results obtained in the Barnes circular maze test as they did not assess cognitive functions in a comparable way.

Several published studies, which showed the positive effect of enriched environment on cognitive functions used tests for cognitive assessment comparable to ours, although their time course and brain lesion model differed from ours (Grabowski et al. 1995, Ohlsson and Johansson 1995, Johansson and Ohlsson 1996). In contrast to studies, using a longer time interval to permit a full development of the influence of enriched environment on cognition, we were not able to unambiguously prove a positive effect with early multisensory rehabilitation (Table 2). Our results show a continuous improvement of cognitive functions after brain trauma which is not statistically different in the standard housing vs. the early rehabilitation model groups. Although the results in the early rehabilitation model group seem better, the statistical significance was achieved only in respect to the search strategy.

To summarize our results, we have confirmed once again the positive effect of early multisensory rehabilitation on the recovery of motor functions after traumatic brain injury. On the other hand, after 15 days of our present study, we have proven a statistically significant positive effect on the recovery of cognitive functions only with respect to the frequency of efficient search strategies. Although the rehabilitation was started very early ( $24 \mathrm{~h}$ after the trauma), we have not observed any occurrence of its negative effect on neuromotor or cognitive functions. Our conclusions thus oppose those studies that found a negative effect of early rehabilitation on functional recovery (Rosenzweig 1966, Humm et al. 1996, 1998, Kozlowski et al. 1996, Risedal et al. 1999, Bland et al. 2000, 2001).

The positive effects of early treatment of functional deficits are comparable with the clinical results in early neurorehabilitation in human patients after brain trauma. It might therefore be reasonable to apply the obtained experimental results to human medical neurorehabilitation care, as the complex motor and cognitive deficits present in rats within the early phase of the disease induced by a brain trauma are analogous to those seen in humans (Nakayama et al. 1994). It is well known that the magnitude of motor deficit in the experimental trauma model discussed here continuously declines within 10 days following the brain trauma and the deficit level correlates well with the trauma level (Lauterborn et al. 1996). On the other hand, the deficits in cognitive functions persist for a much longer time (Neeper et al. 1998, Tao et al. 1998).

In conclusion, we can compare the course of functional recovery outlined above with clinical results of an early neurorehabilitation, which has as its main aim the recovery of sensory motor abilities just after restitution of consciousness and cooperativeness. The treatment of sensory motor functions in this phase is very effective as compared to the results that can be achieved during later phases of rehabilitation. That is why it is very import to support early, intensive neurorehabilitation. However, the treatment aiming at the recovery of cognitive functions is not the main goal in the early phase of rehabilitation, as this is the domain of later rehabilitation. Additional experiments should be done to elucidate the mechanism(s) of this therapy forms in neurorehabilitation.

\section{Conflict of Interest}

There is no conflict of interest. 


\section{References}

BARNES CA: Memory deficits associated with senescence: a neurophysiological and behavioural study in the rat. J Comp Physiol Psychol 93: 74-104, 1979.

BENNETT EL, DIAMOND MC, KRECH D, ROSENZWEIG MR: Chemical and anatomical plasticity of brain. Science 146: 610-619, 1964.

BIERNASKIE J, CHERNENKO G, CORBETT D: Efficacy of rehabilitative experience declines after focal ischemic brain injury. J Neurosci 24: 1245-1254, 2004.

BLAND ST, PILLAI RN, ARONOWSKI J, GROTTA JC, SCHALLERT T: Early overuse and disuse of the affected forelimb after moderately severe intraluminal suture occlusion of the middle cerebral artery in rats. Behav Brain Res 126: 33-41, 2001.

BLAND ST, SCHALLERT T, STRONG R, ARONOWSKI J, GROTTA JC, FEENEY DM: Early exclusive use of the affected forelimb after moderate transient focal ischemia in rats: Functional and anatomic outcome. Stroke 31: 1144-1152, 2000.

CZEH B, SERESS L, NADEL L, BUREŠ J: Lateralized fascia dentata lesion and blockade of one hippocampus: effect on spatial memory in rats. Hippocampus 8: 647-650, 1998.

DALY M: Early stimulation of rodents: a critical review of present interpretations. Br J Psychol 64: 435-460, 1973.

DENENBERG VH, ZARROW MX: Effects of handling in infancy upon adult behaviour and adrenocortical activity: suggestions for a neuroendocrine mechanism. In: Early Childhood: The Development of Self-Regulatory Mechanisms. DN WALCHER, DL PETERS (eds), Academic Press, San Diego, 1971, pp 39-64.

FOX GB, FAN L, LEVASSEUR RA, FADEN AI: Effect of traumatic brain injury on mouse spatial and nonspatial learning in the Barnes circular maze. J Neurotrauma 15: 1037-1046, 1998.

GENTILE AM, BEHESHTI Z, HELD M J: Enrichment versus exercise effects on motor impairments following cortical removals in rats. Behav Neural Biol 47: 321-332, 1987.

GRABOWSKI MM, SORENSEN JC, MATTSSON B, ZIMMER J, JOHANSSON BB: Influence of an enriched environment and cortical grafting on functional outcome in brain infarcts of adult rats. Exp Neurol 133: 96$102,1995$.

GREENOUGH WT, VOLKMAR FR: Pattern of dendritic branching in occipital cortex of rats reared in complex environment. Exp Neurol 10: 491-504, 1973.

HAMM RJ, TEMPLE MD, O’DELL DM, PIKE BR, LYETH BG: Exposure to environmental complexity promotes recovery of cognitive function after traumatic brain injury. J Neurotrauma 13: 41-47, 1996.

HICKS RR, SOARES H, SMITH D, MCINTOSH TK: Temporal and spatial characterization of neuronal injury following lateral fluid percussion injury in the rat. Acta Neuropathol 91: 236-246, 1996.

HUMM JL, KOZLOWSKI DA, JAMES DC, GOTTS JE, SCHALLERT T: Use-dependent exacerbation of brain damage occurs during an early post-lesion vulnerable period. Brain Res 783: 286-292, 1998.

HUMM JL, KOZLOWSKI DA, LAND ST, JAMES DC, SCHALLERT T: Progressive expansion of brain injury by extreme behavioural pressure: Is glutamate involved? Exp Neurol 157: 349-358, 1999.

JOHANSSON BB, BELICHENKO PV: Neuronal plasticity and dendritic spines: effect of environmental enrichment on intact and postischemic rat brain. J Cereb Blood Flow Metab 22: 89-96, 2002.

JOHANSSON BB, OHLSSON AL: Environment, social interaction and physical activity as determinants of functional outcome after cerebral infarction in the rat. Exp Neurol 139: 322-327, 1996.

KOLB B: Brain Plasticity and Behaviour. Lawrence Erlbaum, Hillsdale, NJ, 1995.

KOZLOWSKI DA, JAMES DC, SCHALLERT T: Use-dependent exaggeration of neuronal injury after unilateral sensorimotor cortex lesions. J Neurosci 16: 4776-4786, 1996.

LAUTERBORN JC, RIVERA S, STINIS CT, HAYES VY, ISACKSON PJ, GALL CM: Differential effects of protein synthesis inhibition on the activity-dependent expression of BDNF transcripts: evidence for immediate-early gene responses from specific promoters. J Neurosci 16: 7428-7436, 1996.

LIPPERT-GRÜNER M, MAEGELE M, POKORNÝ J, ANGELOV DN, ŠVESTKOVÁ O, WITTNER M, TROJAN S: Early rehabilitation model shows positive effects on neural degeneration and recovery from neuromotor deficits following traumatic brain injury. Physiol Res 56: 359-368, 2007. 
LIPPERT-GRÜNER M, TERHAAG D: Multimodal early onset stimulation (MEOS) in rehabilitation after brain injury. Brain Injury 14: 585-594, 2000.

LIPPERT-GRÜNER M, WEDEKIND C, ERNESTUS RI, KLUG N: Early rehabilitative concepts in therapy of the comatose brain injured patients. Acta Neurochir Suppl 79: 21-23, 2002a.

LIPPERT-GRÜNER M, WEDEKIND C, KLUG N: Outcome of prolonged coma following severe traumatic brain injury. Brain Injury 17: 49-54, $2002 \mathrm{~b}$.

MAEGELE M, ESTER-BODE T, RIESS P, ANGELOV DN, MCINTOSH TK, NEUGEBAUER EMA, LIPPERTGRÜNER M: Exposure to complex enriched environment combined with multi-modal stimulation promotes recovery of cognitive function after traumatic brain injury in rats. Langenbecks Arch Surg 387: 266 (abstract), 2002.

MCINTOSH TK, VINK R, NOBLE L, YAMAKAMI I, FERNYAK S, SOARES H, FADEN AL: Traumatic brain injury in the rat: characterization of a lateral fluid-percussion model. Neuroscience 28: 233-244, 1989.

NAKAYAMA M, GAHARA Y, KITAMURA T, OSAMU O: Distinctive four promoters collectively direct expression of brain-derived neurotrophic factor gene. Mol Brain Res 21: 206-218, 1994.

NEEPER SA, GOMEZ-PINILLA F, CHOI J, COTMAN CW: Physical activity increases mRNA for nerve growth factor in rat brain. Brain Res 726: 49-56, 1996.

OHLSSON AL, JOHANSSON BB: Environment influences functional outcome of cerebral infarction in rats. Stroke 26: 644-649, 1995.

OKIYAMA K, SMITH DH, THOMAS MJ, MCINTOSH TK: Evaluation of a novel calcium channel blocker, (S)-emopamil, on regional cerebral edema and neurobehavioral function after experimental brain injury. J Neurosurg 77: 607-615, 1992.

PASSINEAU MJ, GREEN EJ, DIETRICH WD: Therapeutic effects of environmental enrichment on cognitive function and tissue integrity following severe traumatic brain injury in rats. Exp Neurol 168: 373-384, 2001.

RISEDAL A, ZENG J, JOHANSSON BB: Early training may exacerbate brain damage after focal brain ischemia in the rat. J Cereb Blood Flow Metab 19: 997-1003, 1999.

ROSENZWEIG MR: Environmental complexity, cerebral change and behavior. Am Psychol 21: 321-332, 1966.

SAATMAN KE, BAREYRE FM, GRANDY MS, MCINTOSH TK: Acute cytoskeletal alterations and cell death induced by experimental brain injury are attenuated by magnesium treatment and exacerbated by magnesium deficiency. J Neuropathol Exp Neurol 60: 183-194, 2001.

SIMSON G, VODDI M, MCINTOSH TK: Nerve growth factor administration attenuates cognitive but not neurobehavioral motor dysfunction or hippocampal cell loss following fluid-percussion brain injury in rats. J Neurochem 65: 2209-2216, 1995.

STEIN SC, CHEN XH, SINSON GP, SMITH DH: Intravascular coagulation: a major secondary insult in nonfatal traumatic brain injury. J Neurosurg 97: 1373-1377, 2002.

SULLIVAN HG, MARTINEZ J, BECKER DP, MILLER JD, GRIFFITH R, WIST AO: Fluid-percussion model of mechanical brain injury in the cat. $J$ Neurosurg 45: 521-534, 1976.

TAO X, FINKBEINER S, ARNOLD DB, SHAYWITZ AJ, GREENBERG ME: $\mathrm{Ca}^{2+}$ influx regulates BDNF transcription by a CREB family transcription factor-dependent mechanism. Neuron 20: 709-726, 1998.

YOUNG D, LAWLOR PA, LEONE P, DRAGUNOW M, DURING MJ: Environmental enrichment inhibits spontaneous apoptosis, prevents seizures and is neuroprotective. Nat Med 5: 448-453, 1999.

ZENG J, MATTSSON B, SCHULZ MK, JOHANSSON BB, SORENSEN JC: Expression of zinc-positive cells and terminals in fetal neocortical homografts to adult rat depends on lesion type and rearing conditions. Exp Neurol 164: 176-183, 2000.

ZHAO LR, RISEDAL A, WOJCIK A, HEJZLAR J, JOHANSSON BB, KOKAIA Z: Enriched environment influences brain-derived neurotrophic factor levels in rat forebrain after focal stroke. Neurosci Lett 305: 169-172, 2001. 